\title{
Development and Performance Evaluation of Self-Generating Enhanced Foam Water Plugging System
}

\author{
Jiexiang Wang, Chang Liu, Guoyu Chu \\ School of Petroleum Engineering, China University of Petroleum, Qingdao, China \\ Email: 1498267564@qq.com
}

How to cite this paper: Wang, J.X., Liu, C. and Chu, G.Y. (2019) Paper Title. Journal of Power and Energy Engineering, 7, 47-54. https://doi.org/10.4236/jpee.2019.711006

Received: July 31, 2019

Accepted: November 24, 2019

Published: November 27, 2019

\begin{abstract}
For the waterflooding of late development on an offshore oilfield has become worse, and some wells group has entered into high water cut-off period, water plugging work becomes particularly important. Due to the limited construction of offshore oilfield, space water supply difficulties, and stability of plugging agent, self-generating enhanced foam has been designed as the aimed block plugging system. The formula is determined as: $23.25 \%$ of $\mathrm{NH}_{4} \mathrm{Cl}+$ $30 \%$ of $\mathrm{NaNO}_{2}+0.1 \%$ of catalyst $+0.6 \%$ of COSL- 3 foaming agent $+0.25 \%$ of HS-type HPAM foam stabilizer. Measurement point of pipe with permeability of $0.5 \mu \mathrm{m}^{2}$ and $2 \mu \mathrm{m}^{2}$ has been used in the plugging and EOR experiments. The experiments show that this system has the selective plugging effect for the heterogeneous formation, especially for middle and posterior part of high permeability formation, and the recovery rate of low permeability pipe is enhanced up to $32.15 \%$.
\end{abstract}

\section{Keywords}

Self-Generating, Enhanced Foam, Blocking Location, Plugging Performance, Water Plugging

\section{Introduction}

With the prolongation of development time, the water flooding effect of some blocks in an offshore oilfield is getting worse year by year. Some well groups have entered the middle and high water cut stage, and the difficulty of "water control and oil stabilization" is gradually increasing [1]. At present, after many rounds of profile control operations in oil fields, the effect is getting worse and worse, so it is necessary to carry out water shutoff in oil wells in time. Because of 
the limited construction space and the difficulty of freshwater supply in offshore oilfields, it is difficult to plug water in oil wells. The plugging agent used in the field should satisfy the conditions of seawater preparation, controllable plugging time, stable formation conditions, easy injection, low formation damage and low cost. Foam water plugging technology is more suitable for the development needs of such high water cut reservoirs. Polymer reinforcement foam can effectively block high permeability layer and large channel, and has higher stability and strength than ordinary foam [2]. At the same time, in view of the difficulty in replenish the foam source of offshore platform, the self ignition system combined with the polymer enhanced foam system is used to make it react in the formation to enhance foam, block high permeability channels and increase the sweep coefficient, so as to achieve the goal of "controlling water and stabilizing oil" [3]. In this paper, the formulation of self ignition strengthening foam water plugging system is studied, and its plugging performance and enhanced oil recovery efficiency are evaluated.

\section{Experiments}

\subsection{Laboratory Reagents and Instruments}

The experimental reagents include seawater instant HPAM, HS HPAM, type I HPAM, type II HPAM, and COSL-3 foaming agent is industrial products; ammonium chloride $\left(\mathrm{NH}_{4} \mathrm{Cl}\right)$, urea $\left(\mathrm{CO}\left(\mathrm{NH}_{2}\right)_{2}\right)$, nitrite $\left(\mathrm{NaNO}_{2}\right)$, ammonium bicarbonate $\left(\mathrm{NH}_{4} \mathrm{HCO}_{3}\right)$, sodium bicarbonate $\left(\mathrm{NaHCO}_{3}\right)$, sodium carbonate $\left(\mathrm{Na}_{2} \mathrm{CO}_{3}\right)$, sodium dihydrogen phosphate $\left(\mathrm{NaH}_{2} \mathrm{PO}_{4}\right)$, sodium citrate $\left(\mathrm{Na}_{3} \mathrm{C}_{6} \mathrm{H}_{5} \mathrm{O}_{7} \cdot 2 \mathrm{H}_{2} \mathrm{O}\right)$, are all analytical pure.

The experimental instruments include: electronic balance (precision $0.0001 \mathrm{~g}$ ), improved Roche foam apparatus, constant control magnetic stirrer, thermoelectric constant temperature water bath, colorimetric bottle, advection pump, electrothermal air drying oven, high temperature and high pressure reactor, intermediate container, six way and sand filling pipe (with three piezometric holes, length $100 \mathrm{~cm}$, inner diameter $2.5 \mathrm{~cm}$ ) and so on.

\subsection{Experimental Method}

\subsubsection{Screening Experiment of Autogenous Gas System}

Under reservoir temperature and pressure, five kinds of autogenous gas systems were added into high temperature and high pressure reactor to carry out reaction experiments, and five kinds of autogenous gas systems were evaluated with gas efficiency as index [4] [5].

\subsubsection{Enhanced Foam Screening Experiment}

The different frother solutions with mass fraction of $0.5 \%$ were prepared by using the salt gas after reaction. The foam was produced by waring-blender mixing method. The best frother was selected from the 4 frother by taking the foam comprehensive value as the index. The foaming agent and the frother solution with different mass fraction were prepared by using the screened frother and salt 
water. The effect of foaming agent dosage on foam performance was studied. Foam agent solution was prepared by 4 foam stabilizer with $0.25 \%$ mass fraction, and foam was produced by mixing method. Foam stabilizer [6] [7] [8] was selected as index.

\subsubsection{Double-Pipe Plugging Performance Evaluation Experiment}

1) Slug design

The injection slug of water shutoff system is designed. The design slug is shown in Table 1.

The main slug injection modes of self strengthening foam main body are slug $1+\operatorname{slug} 4+\operatorname{slug} 5+\operatorname{slug} 4+\operatorname{slug} 5+\operatorname{slug}, 4+\operatorname{Slug} 5$, and each slug size is 0.05 $\mathrm{PV}$.

2) Measurement of plugging performance of double-tube model

The experiment was carried out under the simulated formation conditions of reservoir temperature $65^{\circ} \mathrm{C}$ and backpressure $8 \mathrm{MPa}$. The experimental device of double-pipe plugging is shown in Figure 1.

Table 1. The slug design table.

\begin{tabular}{cc}
\hline Number & Main Component \\
Small Slug 1 & Foaming Agent + Foam Stabilizer Mixture \\
Small Slug 2 & Gas Generator + Catalyst Mixture \\
Small Slug 3 & Initiator + Catalyst Mixture \\
Small Slug 4 & Gas Generator + Foaming Agent + Foam Stabilizer + Catalyst Mixture \\
Small Slug 5 & Initiator + Foaming Agent + Foam Stabilizer + Catalyst Mixture \\
\hline
\end{tabular}

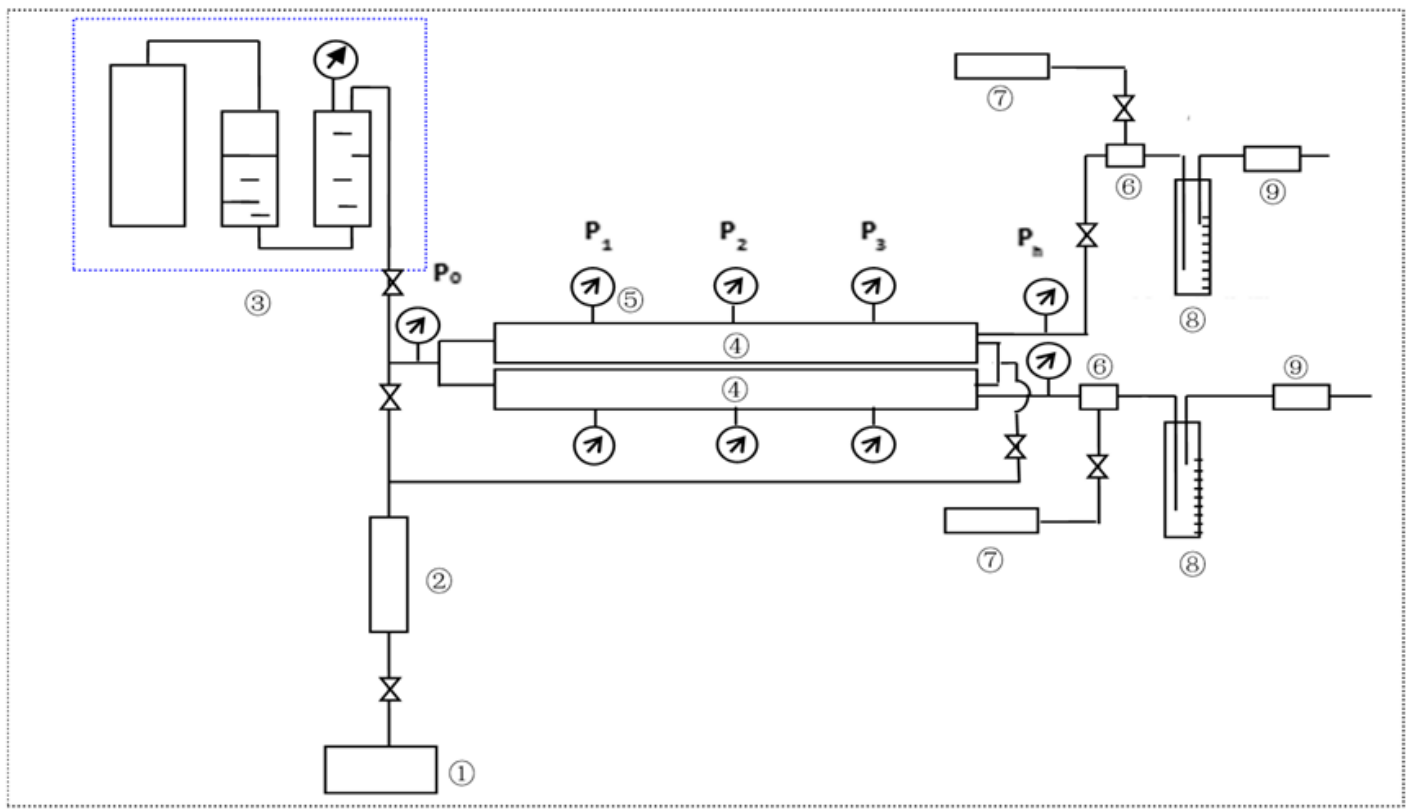

(1): Advection pump; (2): container; (3): Buffer; (4): Reservoir model; (5): Precision Pressure Measuring Instrument; (6): Backpressure valve; (7): Back pressure control; (8): Output liquid collector; (9): Gas Volume Meter.

Figure 1. Double tube displacement experimental apparatus. 
The experimental steps are as follows: 1) Fill the two pipe sand filling model (permeability difference is 4 ), and measure the permeability of two pipes separately; 2) put the sand filling model at constant temperature $24 \mathrm{~h}$ at reservoir temperature; 3) From the outlet of the sand filling model, inject the self strengthening foam system $0.3 \mathrm{PV}$, close the valve gate at both ends of the sand filling pipe, and stew well in the reservoir temperature $10 \mathrm{~h}$; and $1 \mathrm{ml} / \mathrm{m}$. The velocity of in is followed up by water flooding from the injection end. The flow rate of the two pipes and the pressure changes at each pressure measuring point are recorded.

\subsubsection{EOR Determination}

The experimental steps are as follows: 1) Filling double-pipe sand-filling model (permeability range is 4) and measuring the permeability of two pipes separately; 2) Saturating crude oil into two sand-filling pipes respectively, and putting the model at reservoir temperature for 24 hours; 3) Two-pipe water flooding experiment is carried out at the injection rate of $1 \mathrm{~mL} / \mathrm{min}$ until the water production rate reaches $80 \%$; The outlet of the model is injected into the local plugging system at the rate of $1 \mathrm{~mL} / \mathrm{min}$. After the injection is completed, the outlet is closed and the temperature of the reservoir is kept constant for 10 hours; 4) the outlet is opened for production, and the injection end is opened after no liquid production at the outlet, and the water drive is carried out from the injection end (injection rate is $1 \mathrm{~mL} / \mathrm{min}$ ) to the water production rate reaches $98 \%$. 5) The injection seal is calculated. The recovery rate of plugging system is increased.

\section{Results and Analysis}

\subsection{Determination of Autogenic Gas System}

The gas-generating efficiency of the five self-generating systems is shown in $\mathrm{Ta}$ ble 2. The gas-generating efficiency of $\mathrm{Q} 1\left(\mathrm{NaNO}_{2}+\mathrm{NH}_{4} \mathrm{Cl}\right)$ system is the highest, and the reaction time can be controlled within a certain range. At the same time, it was found that the concentration of sodium citrate catalyst had little effect on the self-gas efficiency. Considering the gas volume and solubility, $30 \%$ $\mathrm{NaNO}_{2}+23.25 \% \mathrm{NH}_{4} \mathrm{Cl}+0.1 \%$ catalyst was chosen as the self-gas formulation.

\subsection{Optimum Selection of Foaming Agent}

The performance of four foaming agents is shown in Figure 2. It can be seen that COSL-3 foaming agent is superior to the other three foaming agents. Therefore,

Table 2. The gas production efficiency off different self-generating gas systems.

\begin{tabular}{ccc}
\hline Number & Gas Generation System & Gas Generation Efficiency/\% \\
\hline Q1 & $30 \% \mathrm{NaNO}_{2}+23.25 \% \mathrm{NH}_{4} \mathrm{Cl}$ & 90.33 \\
Q2 & $20 \% \mathrm{CO}\left(\mathrm{NH}_{2}\right)_{2}+46 \% \mathrm{NaNO}_{2}$ & 40 \\
Q3 & $20 \% \mathrm{Na}_{2} \mathrm{CO}_{3}+45.28 \% \mathrm{NaH}_{2} \mathrm{PO}_{4}$ & 15 \\
Q4 & $14.9 \% \mathrm{NH}_{4} \mathrm{HCO}_{3}$ & 45.83 \\
\hline
\end{tabular}


COSL-3 foaming agent is chosen as the foaming agent in this experiment. The performance of COSL-3 foaming agent with different concentration is shown in Figure 3. The optimum concentration of foaming agent is $0.6 \%$.

\subsection{Optimum Selection of Foam Stabilizer}

As shown in Figure 4, the foam solution foam with HS type HPAM has the highest composite value. Therefore, the HS type HPAM with a mass fraction of $0.25 \%$ is chosen as the foam stabilizer for the foam system.

According to Figure 5 and Figure 6, the pressure variation curves of the

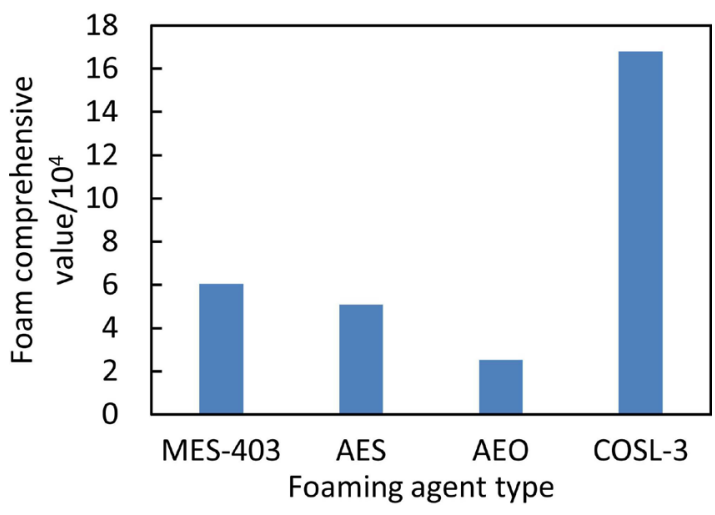

Figure 2. Optimization of foaming agent types.

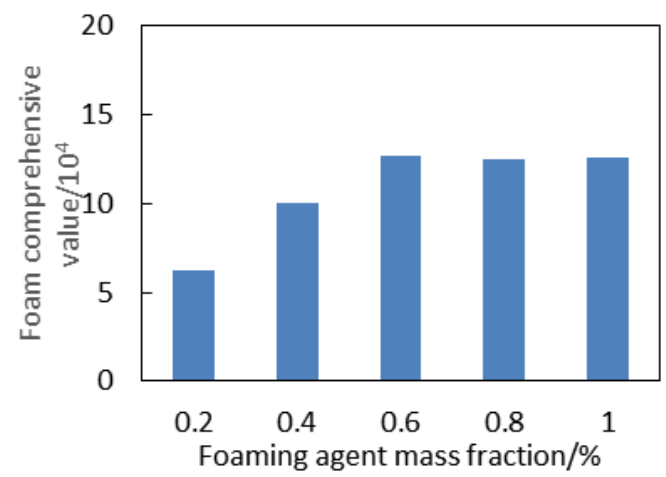

Figure 3. Optimization of foaming concentration types.

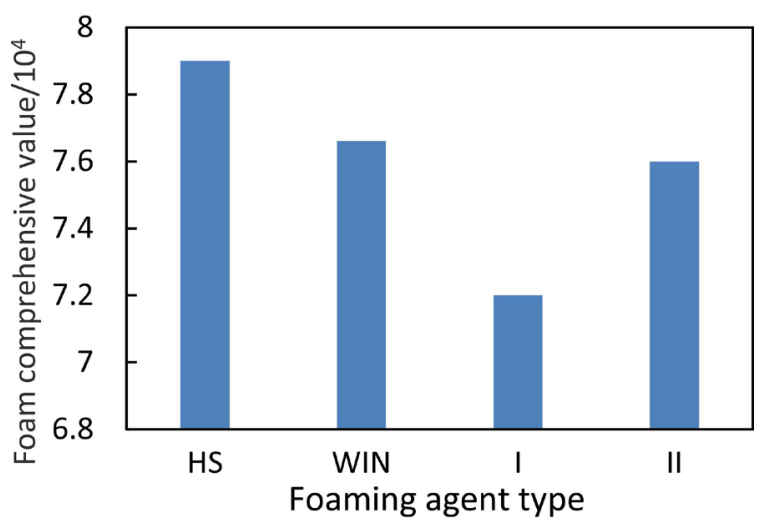

Figure 4. Optimization of foam stabilizer types. 


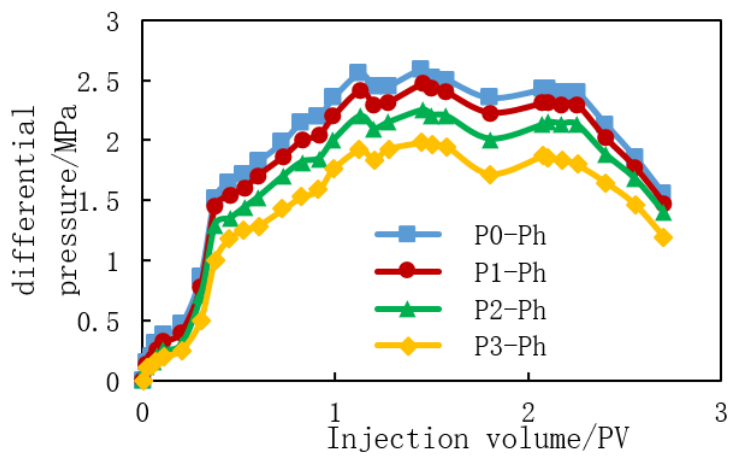

Figure 5. Pressure change of pressure measurement point of low permeability pipe.

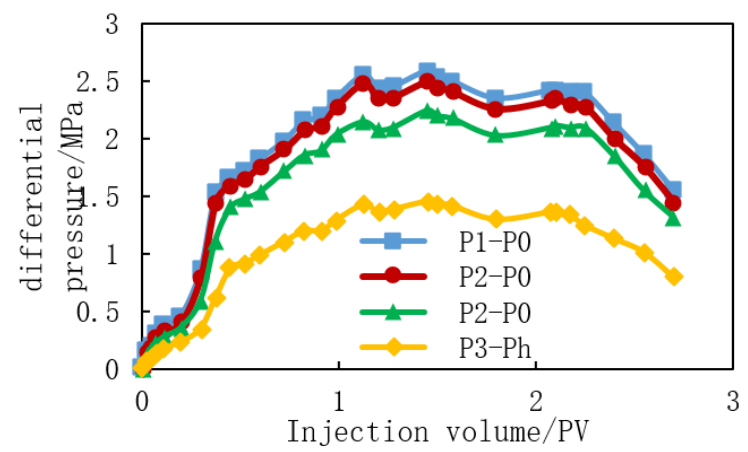

Figure 6. Pressure change of pressure measurement point of high permeability pipe.

pressure points of the two pipes are compared. It is found that the pressure difference between the pressure measuring points of low permeability pipes and the backpressure is larger than that of the back pressure. The pressure difference between the pressure points 0 and 1, 1 and 2, 2 and 3 is relatively small and basically the same, indicating that the foam plugging agent formed in the low permeability pipe is mainly distributed at the outlet side, and the pressure difference between the high pressure pipe pressure gauge 0 and 1,1 and 1 is different from that of the 3 points. The pressure difference between the pressure measuring point 2 and the pressure measuring point 3 and the pressure measuring point 3 and the back pressure increased successively, indicating that the foam plugging agent in the high permeability pipe can reach the middle part of the sand filling model, and can effectively block the rear part of the sand filling model. Therefore, the self strengthening foam system has selective sealing effect on heterogeneous reservoirs, and mainly plugging high permeability reservoirs.

It can be seen from Figure 7 that the diversion rate of high permeability and low permeability pipes is basically stable before plugging (injection volume $<1$ $\mathrm{PV})$. After plugging, the double pipe diversion rate is relatively close after the injection, and the equilibrium state of the shunt can be maintained for a long time. Until the subsequent injection of water is $2.25 \mathrm{PV}$, the diffusing rate of the high permeable pipe begins to pick up and the diversion rate of the low permeability pipe decreases, indicating that the self plugging effect of the foam strengthening system is obvious and has a longer validity period. 


\subsection{Enhanced Oil Recovery}

The injection of self foam enhanced foam slug combination to enhance oil recovery is carried out in a two tube sand filling model (permeability of about 1982 $\times 10^{-3} \mathrm{~m}^{2}$ and $475 \times 10^{-3} \mathrm{~m}^{2}$ ), as shown in Figure 8 .

According to Figure 8, the recovery rate of self strengthening foam is obtained. The following Table 3 shows that the high permeability pipe (HPP) increases the

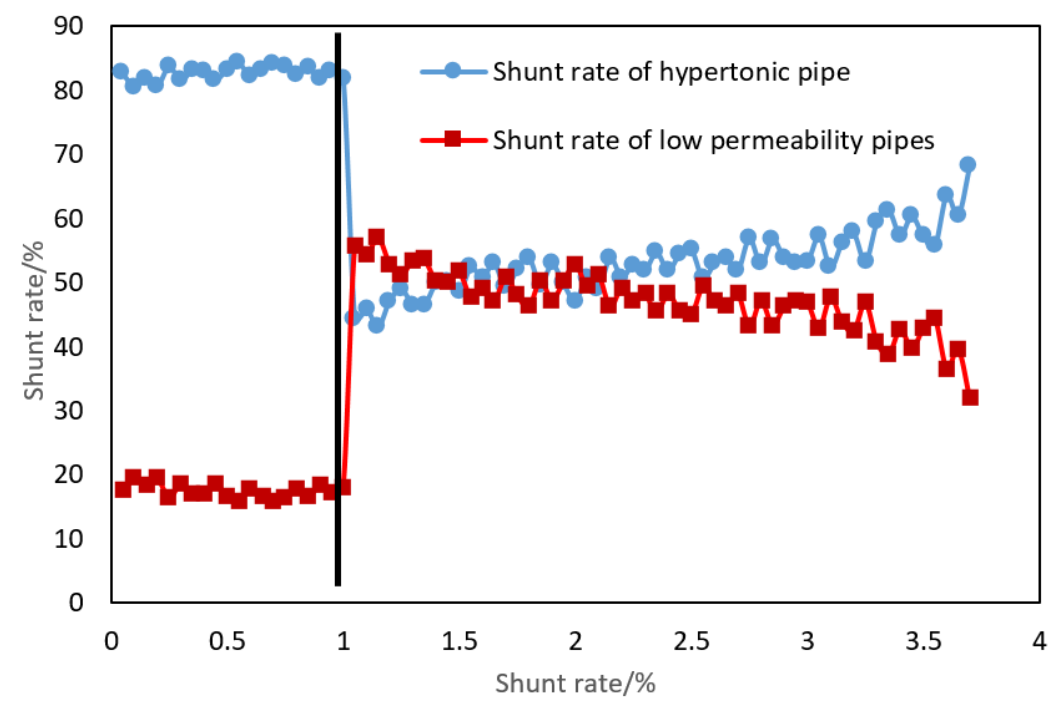

Figure 7. Diversion rate curve.

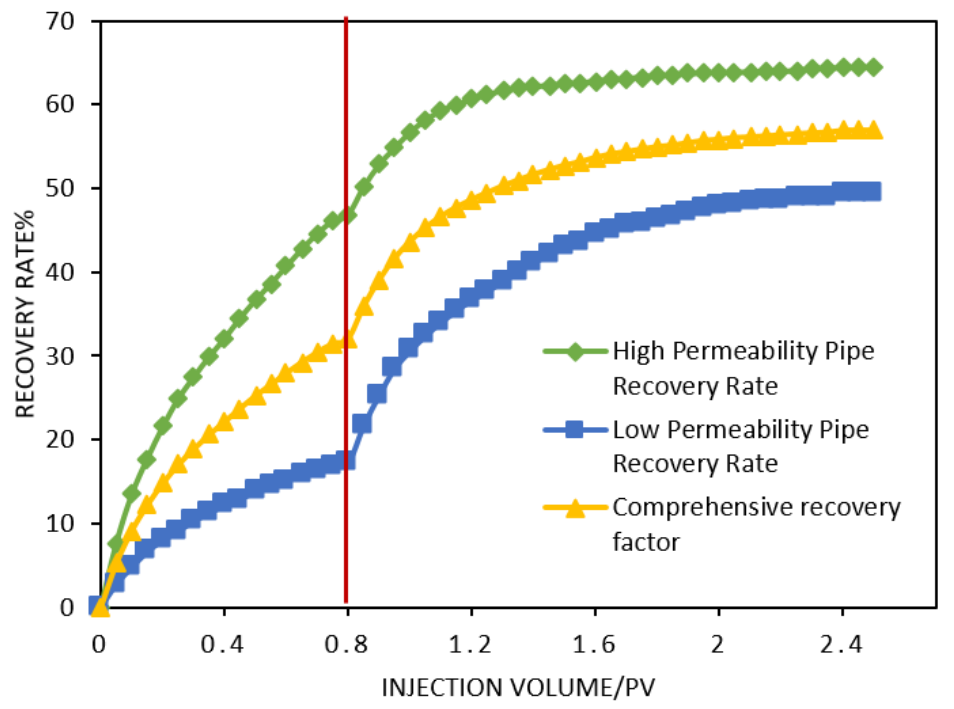

Figure 8. Enhanced oil recovery of self-generating enhanced foam.

Table 3. Comparison of recovery rates in different periods.

\begin{tabular}{ccccccc}
\hline $\begin{array}{c}\text { early stage waterflooding } \\
\text { recovery/\% }\end{array}$ & \multicolumn{2}{c}{$\begin{array}{c}\text { subsequent waterflooding } \\
\text { recovery/\% }\end{array}$} & \multicolumn{3}{c}{ EOR ratio/\% } \\
\hline HPP & LPP & HPP & LPP & HPP & LPP & Total \\
46.90 & 17.24 & 64.46 & 49.39 & 17.56 & 32.15 & 24.85 \\
\hline
\end{tabular}


recovery rate by $17.56 \%$, the low permeability pipe (LPP) increases the recovery rate by $32.15 \%$, and improves the recovery ratio by $24.85 \%$.

\section{Conclusions}

1) Through the optimization of different systems, the formulation of the self strengthening foam system developed is $0.6 \%$ COSL-3 foaming agent $+0.25 \%$ $\mathrm{HPAM}+30 \% \mathrm{NaNO}_{2}+23.25 \% \mathrm{NH}_{4} \mathrm{Cl}+0.1 \%$ catalyst.

2) The self strengthening foam system has better selective plugging effect on heterogeneous strata under reservoir conditions, and mainly plugging the latter part of the high permeability reservoir.

3) The experiment of increasing oil recovery by plugging water by parallel sand filling pipe shows that the enhanced oil recovery rate of self strengthening foam low permeability pipe can reach $32.15 \%$, and the double pipe comprehensive recovery ratio can reach $24.85 \%$. The system has good water plugging effect.

\section{Conflicts of Interest}

The authors declare no conflicts of interest regarding the publication of this paper.

\section{References}

[1] Liu, Y.G., Xu, W.J. and Jiang, W.D. Research and Practice of Regulation and Flooding Technology for Offshore Oil Fields. Petroleum Science \& Technology Forum.

[2] Yu, H., Wang, Y., Ji, W., et al. (2011) Study of a Profile Control Agent Applied in an Offshore Oilfield. Petroleum Science \& Technology, 29, 1285-1297. https://doi.org/10.1080/10916466.2010.525587

[3] Zhou, M.L., Liu, F., Huang, W., Zhang, C.X. and Deng, Y.X. (2012) Application and Effect Analysis of Profile Control Technology in Chengdao Oilfield. Offshore Oil, 32, 74-78.

[4] Zhao, F.L., Dai, C.L. and Wang, Y.F. (2006) Water Control Technology for Enhancing Oil Recovery in Offshore Oilfields. Journal of China University of Petroleum, Natural Science Edition, 30, 53-58.

[5] Zhang, Z., Han, H., Shen, J., et al. (2014) Study on Adaptability of Nitrogen Foam to Control Profile in Offshore Oilfield. Advances in Petroleum Exploration \& Development, 7, 72-77.

[6] Yang, Z.C., Zheng, J.L. and Weng, D.L. (2017) Self Generating System And Influencing Factors of Gas Generation Efficiency of Self Generated CO2 Foam in Bohai Oil Field. Progress in Fine Petrochemical Industry, 18, 38-40.

[7] Xu, G.R., Ju, Y., Pang, C.Y., et al. (2017) Study on Optimization of Self-generating System in Offshore Oilfields. Inner Mongolia Petrochemical Industry, No. 1, 90-93.

[8] Zou, B., Liu, D.Q. and Tian, T. (2010) Study on the Performance of High Temperature Self Foaming Foam System. Fine Petrochemical Progress, 11, 19-21. 